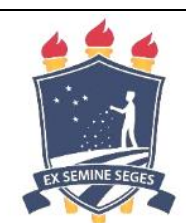

Ectoparasitismo por Struthiolipeurus rheae (Harrison, 1916) em emas criadas em cativeiro

[Ectoparasitism by Struthiolipeurus rheae (Harrison, 1916) in rheas bred in captivity]

"Comunicação Breve/Short Communication"

\author{
Juliane Nunes Pereira Costa*, Fernanda Samara Barbosa Rocha, Laylson da Silva Borges, \\ Iuliana Marjory Martins Ribeiro, Ivete Lopes de Mendonça
}

Centro de Ciências Agrárias, Universidade Federal do Piauí, Teresina-PI, Brasil.

*Autor para correspondência/Corresponding author: E-mail: july-hp@ hotmail.com

\begin{abstract}
Resumo
Os malófagos são piolhos mastigadores, encontrados em aves e mamíferos. Nas emas (Rhea americana) podem causar grandes prejuízos ao comércio, devido à perda da qualidade das plumas, danificação das penas, lesões na pele e debilidade. Sendo assim, objetiva-se com o estudo relatar a infestação por piolhos em emas criadas em cativeiro. Os piolhos foram preservados em álcool 70\%, clarificados com lactofenol e montadas as lâminas para observação em microscópio óptico. Nas emas observou-se alterações como desidratação, pele descamada e áspera, penas deformadas, falhadas e opacas e presença de piolhos malófagos da espécie Struthiolipeurus rheae.
\end{abstract}

Palavras-chave: malófagos; Rhea americana; parasitismo.

Mallophaga are chewing lice found in birds and mammals. In emas (Rhea americana), they can cause great damages to the trade, due to the loss of the quality of feathers, damage of the feathers, injuries in the skin, and weakness. Thus, the objective of this study was to report lice infestation in emas bred in captivity. The lice were preserved in $70 \%$ alcohol, clarified with lactophenol and the slides assembled for observation under an optical microscope. In the emas, there were alterations such as dehydration, peeling and rough skin, deformed, failed and opaque feathers, and presence of Mallophaga lice of Struthiolipeurus rheae.

Keywords: Mallophaga; Rhea americana; parasitism.

Na Ordem Phthiraptera são encontrados os malófagos, piolhos mastigadores, que podem parasitar aves e mamíferos. Nas emas (Rhea americana) são observados preferencialmente nas penas das asas, base do pescoço e nas plumas. Os malófagos em sua maioria são espécies específica e alimenta-se de escamas epidermais, de penas e de secreções sebáceas de aves e mamíferos (Urquhart et al., 1998; Ahid et al., 2008).

A transmissão ocorre por contato direto com um único hospedeiro. As fêmeas realizam a ovoposição na base das penas, os ovos geralmente são esbranquiçados podendo ser visualizados a olho nu e eclodem quatro a sete dias após a postura. O ciclo de vida apresenta cinco fases: ovo, três mudas de ninfas e adulto, com duração de duas a três semanas (Ahid et al., 2008; Fagundes et al., 2009).

Podem ser identificados segundo características morfológicas da espécie, tais como, cabeça arredondada, mais longa que larga, comprimento iguais das garras, antenas de cinco segmentos e as fêmeas possuem ventralmente três pares bilaterais de manchas escuras nos últimos segmentos do abdome (Weisbroth e Seelig, 1974; Fagundes et al., 2009).

A presença desse ectoparasita pode causar grandes prejuízos ao produtor, devido à perda da qualidade das plumas, danificação das penas, além de comprometer no ganho de peso das aves. Uma elevada carga parasitária de piolhos pode levar ao prurido intenso, irritação, lesões na pele e debilidade. Podendo ser reflexo de alguma outra 
condição subjacente, como por exemplo, a má nutrição ou doenças crônicas, fazendo com que a ave deixe de realizar seus hábitos de limpeza, proliferando assim a infestação (Urquhart et al., 1998; Sinkoc et al., 2005; Fagundes et al., 2009).

No Brasil, o parasitismo por Struthiolipeurus rheae (Harrison, 1916) já foi relatado infestando emas nos estados de São Paulo (Silva et al., 2004), Rio Grande do Sul e Minas Gerais (Sinkoc et al., 2005), Rio Grande do Norte (Ahid et al., 2008) e no Piauí (Moura et al., 2012).

Devido à dificuldade de se obter informações do ectoparasitismo em aves silvestres no país e considerando a importância dos criadouros conservacionistas, o presente estudo teve como objetivo relatar a infestação natural por piolhos $S$. rheae em emas criadas em cativeiro.

O estudo foi desenvolvido com 19 emas $(R$. americana) criadas em cativeiro no Núcleo de Estudos e Pesquisas em Animais Silvestres (NEPAS) da Universidade Federal do Piauí, localizado no município de Teresina, durante o mês de agosto de 2017. Para a realização do exame clínico as aves foram capturadas pelo tratador que as conteve fisicamente pela base das asas, firmemente junto ao solo, em seguida colocou-se um capuz para manter o ambiente escuro facilitando o manejo, conforme recomendação de Cubas et al. (2014).

Das 19 emas avaliadas, 14 estavam infestadas e destas foram coletadas 18 amostras de ectoparasitas nas penas das asas, dorso e base do pescoço. Os piolhos foram preservados em álcool $70 \%$ e encaminhados ao Laboratório de Sanidade animal (LASAN), cinco destes foram posteriormente clarificados com lactofenol e montadas as lâminas para observação em microscópio óptico com objetiva de 4x e 10x, em seguida, identificados segundo características descritas por Carriker (1945), Weisbroth e Seelig (1974), e Fagundes et al. (2009).

No exame clínico das emas observou-se alterações como desidratação, pele descamada e áspera, penas deformadas, falhadas e opacas e presença de piolhos malófagos nas penas das asas, dorso e base do pescoço. Esses ectoparasitas foram identificados como sendo da família Philopteridae e da espécie $S$. rheae (Figura 1).

As principais características morfológicas para descrever a espécie são a presença de três pares bilaterais ventrais de machas escuras nos últimos segmentos abdominais da fêmea, garras de comprimentos equivalentes e antena composta por cinco segmentos (Weisbroth e Seelig, 1974; Ahid et al., 2008; Fagundes et al., 2009), correspondendo com as características dos piolhos encontrados no presente trabalho.

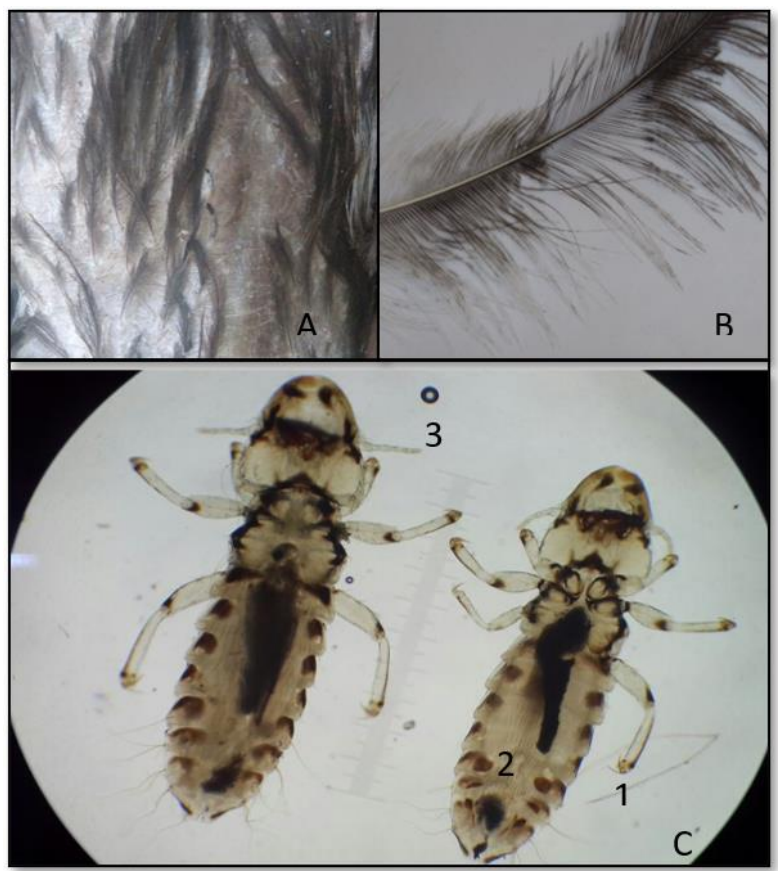

Figura 1. A - Dorso de uma ema com presença de pele descamada. B - Pena de Rhea americana danificada. C - Struthiolipeurus rheae: 1 - garras de comprimentos equivalentes. 2 - Manchas escuras nos últimos segmentos abdominais da fêmea. 3 Antena com cinco segmentos (objetiva de 10x).

Destaca-se que, os piolhos mastigadores estavam presentes nas penas do dorso das aves, próximo a base do pescoço e asas, confirmando a predileção destes por estas áreas, conforme relatados em outros trabalhos (Silva et al., 2004; Moura et al., 2012). Não houve ocorrência destes, nas proximidades da cauda.

Conclui-se que as emas mantidas no criatório do Núcleo de Animais Silvestres da Universidade Federal do Piauí estavam infestadas por piolhos da espécie Struthiolipeurus rhea. A presença destes malófagos evidência a necessidade de adoção de um protocolo de controle de ectoparasitas em aves silvestres de cativeiro.

\section{Conflito de Interesse}

Os autores declaram não existir conflito de interesse.

\section{Comitê de Ética}

A presente pesquisa teve autorização da Comissão de Animais Silvestres, Comitê de Ética em Experimentação Animal - CEEA/UFPI, sob o número 360/17 e pelo Sistema de Autorização e 
Informações em Biodiversidade (Sisbio), sob o número 58834-2.

\section{Referências}

Ahid, S.M.M.; Oliveira, M.F.; Suassuna, A.C.D. Ectoparasitismo por Struthiolipeurus (HARRISON, 1916) (Phthiraptera: Philopteridae) em Rhea americana (Rheiformes: Rheidae) em condições cativas no município de Mossoró, Rio Grande do Norte, Brasil. Ciência Animal Brasileira, 9(3): 767-770, 2008.

Carriker Jr., M.A. New species of Struthiolipeurus, Multicola, Microtenia and Pseudocophorus. Boletín de Entomología Venezolana, 4(4): 165-189, 1945.

Cubas, Z.S.; Silva J.C.R.; Catão-Dias, J.L. Tratado de animais selvagens: medicina veterinária. São Paulo: Roca, 2014. p.2470.

Fagundes, T.F.; Soleiro, C.A.; Menezes, R.C.A.A. Struthiolipeurus rheae Harrison, 1916 (Phthiraptera: Philopteridae) infestando avestruzes (Struthio camelus) em uma criação no Município de Três Rios, RJ. Revista Brasileira Parasitologia Veterinária, 18(1): 80-82, 2009.

Moura, S.G.; Mendonça, I.L.; Moura, W.R.A.; Vieira, R.J.; Júnior, A.M.C.; Souza, J.A.T.; Júnior, A.S. Avaliação da infestação de piolhos mastigadores (Struthiolipeurus rheae) em emas (Rhea americana) mantidas em criadouro comercial no estado do Piauí. Semina: Ciências Biológicas e da Saúde, 33(1): 77-82, 2012.

Pesenti, T.C.; Silva, D.S.; Bertacco, L.L.; Brum, J.G.W.; Muller, G. Registro de Struthiolipeterolichus sculpturatus e Struthiolipeurus rheae em Struthio camelus no Rio Grande do Sul, Brasil. Ciência Rural, 39(8): 2546-2549, 2009.

Silva, S.O.; Oliveira, H.H.; Friccielo, R.H.; SerraFreire, N.M. Malófagos parasitas de aves campestres cativas do zoológico municipal Quinzinho de Barros, Sorocaba, Estado de São Paulo, Brasil. Entomología y Vectores, 11(2): 333-339, 2004

Sinkoc, A.L.; Muller, G.; Brum, J.G.W.; Soares, M.P.; Oliveira, L.T.; Gonçalves, I.P.D. Ocorrência de Struthiolipeurus rheae (Phthiraptera: Ischnocera: Philopteridae) em Rhea americana (Rheiformes: Rheidae) no Brasil. Arquivos do Instituto Biológico. 72(4): 535-538, 2005.

Urquhart, G.M.; Armour, J.; Dunn, A.M.; Jennings, F.W. Parasitologia veterinária. $2^{\mathrm{a}}$ ed. Rio de Janeiro: Guanabara Koogan, 1998, p.147-153.

Weisbroth, S.H.; Seelig, A.W. Struthiolipeurus rheae (Mallophaga: Philopteridae), an ectoparasite of the common Rhea (Rhea americana). Journal Parasitology, 60(5): 892-894, 1974. 